\title{
Centrex: uma proposta de sistema de forças orto- dônticas para atuação no centro de resistência
}

\author{
José Kleber Soares de Meireles*, Weber Ursi**
}

\begin{abstract}
Resumo
Objetivo: este trabalho propõe um novo sistema de forças ortodônticas que visa eliminar ou diminuir alguns efeitos secundários da mecânica ortodôntica, como as inclinações, extrusões e perdas de ancoragem. Por meio de uma revisão crítica da literatura sobre a biomecânica, e de ilustrações detalhadas dos mecanismos, procura-se apresentar didaticamente o seu conceito e sua proposta de funcionamento. Conclusões: embora já existam outras tentativas de diminuir efeitos indesejados da mecânica ortodôntica, como o Power-arm de Andrews e a mecânica com arcos segmentados, ainda assim, sua utilização tem se mostrado muito distante de uma unanimidade na prática clínica ortodôntica. O Centrex talvez se mostre como uma forma de melhorar a mecânica ortodôntica pela diminuição de alguns efeitos indesejados.
\end{abstract}

Palavras-chave: Ancoragem ortodôntica. Mini-implantes. Centro de resistência.

\section{INTRODUÇÃO}

Desde o advento das primeiras mecânicas ortodônticas, os profissionais têm enfrentado um problema comum a todas elas: o fato da colocação dos acessórios ser feita na coroa dos dentes, muito distante da região onde a resultante do sistema de forças atua - o centro de resistência do dente ou de um conjunto de dentes. O resultado desta limitação é que os dentes apresentam, além do movimento desejado, uma tendência a se inclinarem e a extruírem na direção do movimento. Este efeito secundário, certamente, não contribui para a boa condução do caso, gerando a necessidade de um tempo de tratamento maior do que o normal e aumentando o risco de efeitos danosos ao periodonto de sustentação e/ou às raízes dos dentes.

Por mais que se tenha procurado desenvolver artifícios para se evitar estes efeitos secundários, por meio de recursos no próprio braquete, tais como braquetes de translação com Power-arm, de Andrews; de acessórios como braços de força ajustados nos braquetes e/ou tubos; ou de mecânicas segmentadas, com a aplicação de contra-momentos para anular o efeito de inclinação, ainda assim essa questão não está resolvida de maneira satisfatória dentro da mecânica ortodôntica. Seria interessante, portanto, o desenvolvimento de um sistema que, de maneira controlada e ajustável, pudesse transmitir a força o mais próximo possível do centro de resistência de um dente ou mesmo de um conjunto de dentes. O intuito deste trabalho é justamente este, propor um sistema que possa ser ajustado à maioria das situações clínicas que necessitem de controle axial, com um mínimo de atrito, propiciando uma movimentação controlada e rápida.

* Especialista em Ortodontia pela PROFIS USP-Bauru. Professor dos cursos de aperfeiçoamento e especialização em Ortodontia da ABO-Bahia.

** Mestre e Doutor em Ortodontia - FOB/USP. Professor Doutor da Faculdade de Odontologia de São José dos Campos - UNESP. 


\section{BIOMECÂNICA DA MOVIMENTAÇÃO ORTODÔNTICA}

A compreensão da Física envolvida nos planejamentos e ajustes dos aparelhos ortodônticos permite um melhor domínio da mecânica aplicada, bem como a minimização dos efeitos colaterais inoportunos, eventualmente produzidos durante o tratamento. Alguns conceitos básicos devem ser revisados, para melhor entendimento da mecânica ortodôntica:

- Centro de massa: é o ponto onde se "concentra" a massa de um corpo livre no espaço. A aplicação de uma força no centro de massa de um corpo de qualquer dimensão faz com que todos os pontos desse objeto se desloquem numa mesma direção e magnitude, constituindo o movimento de translação. Uma força aplicada fora deste ponto geraria no objeto um movimento de inclinação ${ }^{7}$.

- Centro de resistência (CRes): o dente, por sua vez, não está livre no espaço, a sua raiz é circundada pelas estruturas de sustentação do periodonto. Nesse caso, existe um ponto análogo que é denominado centro de resistência. Uma força simples, atuando no centro de resistência do dente, produz um efeito de translação deste dente. $\mathrm{O}$ centro de resistência de um dente unirradicular está posicionado no terço coronal da raiz, que pode ser obtido multiplicando-se por 0,33 a distância entre a crista óssea e o ápice da raiz. Num dente multirradicular, o centro de resistência está localizado próximo à bifurcação ou trifurcação deste ${ }^{7}$.

- Centro de rotação (CRot): quando uma força é aplicada fora do centro de resistência do dente, este sofre um movimento que pode ser definido como uma combinação de translação e rotação. A medida desta tendência de rotação é chamada de momento da força $(\mathrm{MF})^{18}$ e é obtida por meio do produto da magnitude da força (F) pela distância (d) perpendicular entre a linha de ação de força e o centro de resistência. Sua magnitude é expressa em $\mathrm{g} \mathrm{x} \mathrm{m}^{8}$. A sua representação esquemática é dada pela continuação da linha de ação de força em torno do CRes. A aplicação de uma força na coroa gera um movimento que leva o ápice radicular numa direção e a porção cervical da raiz e a coroa para a direção oposta, com um giro ao redor do centro de rotação, que não se movimenta em qualquer direção (Fig. 1).

- Binários: são duas forças de mesma magnitude e direção, em sentidos opostos, não colineares. O binário é o único sistema de forças que pode causar o movimento de rotação pura de um corpo. Qualquer força simples aplicada fora do CRes resulta num movimento de deslocamento do CRes no sentido da linha de ação da força, enquanto o dente gira em torno do seu CRot que, nesse caso, não coincide com o CRes. Por outro lado, quando um binário é aplicado, a movimentação do CRes em qualquer um dos sentidos é coibida pela força oposta. Assim, o CRes não se movimenta. As duas forças do binário tendem a girar o dente em torno do CRes, fazendo que este coincida com o CRot. Mesmo quando as linhas de ação de força não são eqüidistantes do CRes, ainda produzem a mesma tendência de rotação do dente ${ }^{14}$. Um binário pode ser aplicado no braquete com o uso de fios retangulares, o que chamamos de torque, e gerar a mesma tendência de rotação no dente.

A associação de uma força mais um momento atuando no CRes pode proporcionar a obtenção dos movimentos ortodônticos desejados. Ou seja, em linguagem ortodôntica, diz-se que é a relação entre o momento e a força $(\mathrm{M} / \mathrm{F})$ no CRes que

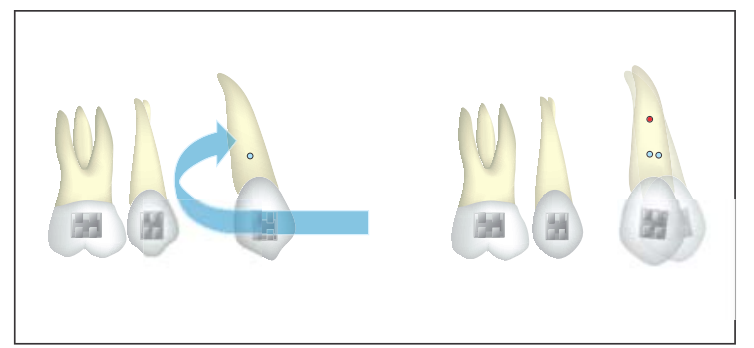

FIGURA 1 - Uma forma de entender o tipo de momento gerado é continuar a linha de ação da força ao redor do centro de resistência. A força em sentido distal aplicada ao braquete do canino gera um momento em sentido horário, que tende a levar a coroa para distal e a raiz para mesial, com o centro de rotação localizado entre o centro de resistência e o ápice do dente (rotação descontrolada). 
regulamenta o tipo de estímulo desejado sobre o ligamento periodontal e a superfície radicular.

\section{MOVIMENTOS DENTÁRIOS CONSEGUIDOS EM ORTODONTIA}

No interesse de simplificar o entendimento, não serão abordados os aspectos tridimensionais da movimentação dentária, as representações serão feitas bidimensionalmente. É importante terse em mente que é possível a obtenção de qualquer tipo de movimentação dentária através da manipulação dos sistemas de forças de modo a se conseguir o CRot desejado. Existem basicamente 3 movimentos aplicados aos dentes por aparelhos ortodônticos: os movimentos de translação, de rotação pura e a combinação desses dois. A translação pressupõe a movimentação de todos os pontos do dente em uma única direção, o que permite uma distribuição equilibrada de forças ao longo do ligamento periodontal, este movimento ocorre quando uma força atua diretamente no CRes do dente. Em tal situação, diz-se que o CRot está localizado no infinito.

A rotação pura, como descrito anteriormente, ocorre quando o CRot coincide com o CRes do dente, ou seja: numa vista vestibular, a coroa move-se para um lado e a raiz para o outro. Neste caso, existe uma concentração de forças no ápice do dente, associada a uma compressão na crista óssea, em sentidos contrários.

Os conceitos mecânicos básicos, revisados aqui, serão retomados no decorrer do artigo. É de extrema importância o completo domínio dos fundamentos biomecânicos para a condução eficiente de um tratamento ortodôntico sem efeitos negativos sobre os dentes e o periodonto. O sucesso na Ortodontia pode ser definido como a obtenção dos resultados planejados no menor tempo e com o menor custo biológico possível. É precisamente nessa direção que a especialidade ortodôntica busca evoluir, tanto no desenvolvimento de novas aparatologias quanto no aprimoramento das diversas técnicas existentes.
É interessante perceber a mudança filosófica em andamento na Ortodontia moderna. O paradigma estabelecido pelas idéias funcionais herdadas da prótese, no início do século XX, pressupunha a manutenção de todos os dentes em oclusão como forma de garantir uma excelência funcional. A norma filosófica sobreposta a esta indicava a rigidez posicional dos dentes, estabelecida por preceitos cefalométricos rigorosos. Nesta fase, a obtenção intransigente de uma oclusão ideal era o objetivo que balizava a mecânica ortodôntica. A essas idéias foram se sobrepondo ou se somando outras que representavam o pensamento filosófico da época.

Não cabe a nós, terapeutas desta época atual, julgar os princípios filosóficos que regiam as condutas clínicas anteriores, especialmente porque o futuro será o juiz de nossos conceitos atuais. Porém, parece coerente que a sobreposição de verdades científicas temporais nos tenha conduzido a este novo paradigma que pressupõe a individualização de diagnóstico e tratamento.

É possivel notar que essa mudança de pensamento coincide com o grande aumento do contingente de indivíduos adultos em busca de tratamento ortodôntico. É até mesmo possível que esses novos conceitos sejam os grandes responsáveis por possibilitar tratamentos em indivíduos antes excluídos da terapia ortodôntica. Tome-se, por exemplo, o caso de pessoas com problemas periodontais e grandes discrepâncias oclusais: tais tratamentos seriam imensamente dificultados caso o objetivo fosse uma relação de Classe I perfeita. Para tal paciente, pode ser suficiente a melhora do padrão oclusal e a aquisição de uma função normal, sem interferências, preenchendo os requisitos de uma oclusão mutuamente protegida.

A ocorrência de problemas periodontais não é a única consideração importante a se fazer em casos de pacientes adultos; deve-se considerar também a ausência de crescimento, restaurações adaptadas à má oclusão, a presença de alterações sistêmicas, a ocorrência de disfunção temporomandibular, além 
da ausência de dentes. Deve-se, também, levar em consideração o nível de exigência desses pacientes e o tempo a que aceitariam ser submetidos ao tratamento ortodôntico.

Para melhor entendimento das diferenças pertinentes à mecânica ortodôntica, vamos inicialmente discorrer sobre os princípios que regem a movimentação dentária induzida.

O periodonto de sustentação constitui-se de um sistema complexo de células, fibras, matriz e componentes neurovasculares, tendo como componentes estruturais o cemento, ligamento periodontal e osso alveolar. Ele é responsável pela manutenção da posição dentária e pela dissipação das forças oriundas das funções oclusais através do osso alveolar ${ }^{19}$. O ligamento periodontal é a estrutura responsável pelo processo de movimentação dentária através do osso. As forças ortodônticas agem no processo de movimentação dentária através da alteração do fluxo sanguíneo e do ambiente eletromecânico do ligamento periodontal, alterando o equilibrio homeostático do ligamento (LPD) em duas áreas: o lado de compressão e o lado de tensão. Inicia-se, com isso, uma "cascata" biomecânica e celular que rearranja o contorno ósseo alveolar.

No lado de compressão, a diminuição do espaço disponível causa nas células presentes no LPD - como, por exemplo, os fibroblastos, cementoblastos e osteoblastos - a deformação da sua estrutura e a diminuição da oxigenação pela compressão dos vasos sanguíneos do LPD. Tais eventos, denominados, respectivamente, de estresse celular mecânico e funcional, suscitam a liberação de mediadores químicos que induzem a instalação do processo inflamatório responsável pelo início da reabsorção frontal do osso alveolar.

Enquanto forças leves aplicadas ao dente resultam, no lado de pressão, numa obstrução parcial da vascularização do LPD com conseqüente reabsorção óssea frontal, forças pesadas obliteram a luz dos vasos e causam necrose dos tecidos vizinhos pela restrição de oxigênio e nutrição.

Ao contrário da remodelação fisiológica induzi- da pela aplicação de forças leves, as forças pesadas causam a hialinização do LPD, reabsorção à distância, além de estarem envolvidas na reabsorção radicular. A movimentação dentária resultante de uma força leve é lenta e gradual, enquanto aquela gerada pela aplicação de forças pesadas é abruptamente iniciada e finalizada, coincidindo com o colapso do osso necrosado ${ }^{22,23,25,26}$. Portanto, a magnitude de força ideal para movimentação dentária não deve ser maior que o mínimo necessário para induzir tal movimentação. Forças intensas são aplicadas, freqüentemente, em casos de retração dos dentes anteriores superiores e inferiores, quando da extração de pré-molares, especialmente porque à força de retração deve-se somar a força aplicada ao dente para contrapor a tendência de inclinação (momento) das unidades envolvidas no movimento distal, o que se consegue com torques nos fios retangulares (Fig. 2). É importante ressalvar que os torques nos fios são necessários mesmo quando da utilização de aparelhos totalmente programados, visto que é a individualização de tais torques

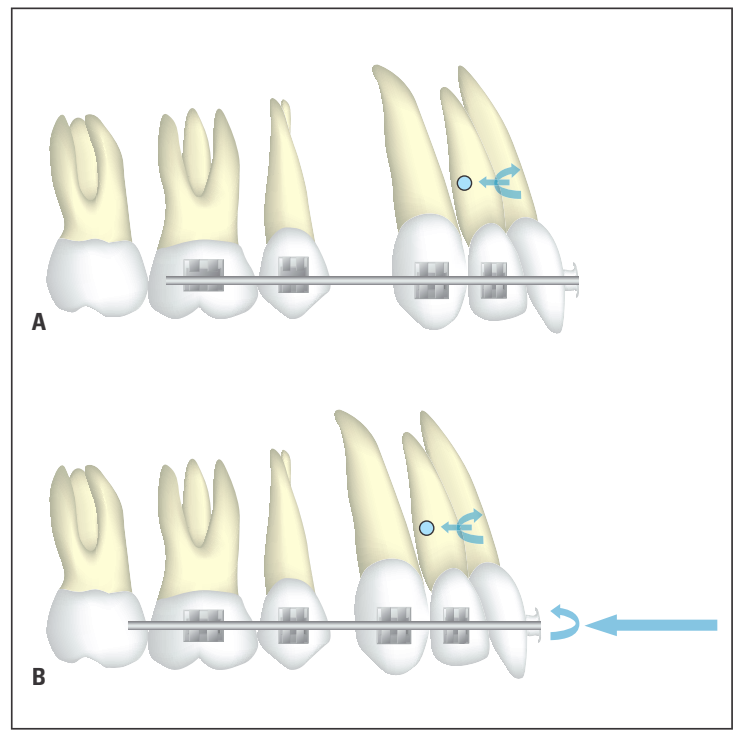

FIGURA 2 - A retração dos dentes anteriores superiores, feita com aplicação da força na altura das coroas dentárias (A), gera um momento neste conjunto de dentes, que tende à rotação no sentido horário. A utilização de fios retangulares, nesta fase, permite 0 controle posicional (inclinação) desses dentes através da aplicação de torques linguais de raiz, para contrapor-se à tendência de perda de inclinação gerada pela força de retração (B). 
- durante a movimentação dentária e na fase de finalização - que possibilita uma maior eficiência mecânica e um melhor refinamento no acabamento do tratamento ortodôntico. No decorrer do artigo, será explicada uma maneira de diminuir a magnitude da força presente no sistema.

Outro fator complicador da mecânica ortodôntica, particularmente na mecânica de retração dos dentes anteriores, é a reabsorção óssea presente em determinados indivíduos. A reabsorção óssea alveolar pode ser derivada de um processo patológico ou parte de um processo fisiológico que determina uma perda média anual de aproximadamente $0,017 \mathrm{~mm}$ de osso alveolar ${ }^{10}$. O tratamento ortodôntico em adultos, como demonstrado em alguns estudos clínicos ${ }^{5,13}$, pode aumentar suavemente esta perda de suporte periodontal, o que tende a causar alguns problemas, especialmente no tocante à biomecânica envolvida no tratamento. À medida que o osso alveolar migra apicalmente, o centro de resistência do dente também migra e sua distância em relação à crista alveolar diminui. Esta distância em um dente com periodonto sadio é de aproximadamente $5,5 \mathrm{~mm}$ em relação à crista óssea, caindo para $1,6 \mathrm{~mm}$ em um dente com perda óssea de $8 \mathrm{~mm}$.

Sendo a tendência de inclinação de um dente determinada pelo produto entre a força e a distância perpendicular da linha de ação da força ao centro de resistência do dente, uma força ortodôntica considerada fisiológica, quando aplicada em dentes com suporte periodontal normal, pode ser excessiva quando o dente apresentar suporte periodontal diminuído (Fig. 3). Tal movimentação pode aumentar a tendência de perda óssea, além de favorecer a reabsorção apical pelo aumento de pressão nesta área, causado pela maior tendência de inclinação do dente ${ }^{3}$.

Para Geramy ${ }^{12}$, a relação $\mathrm{M} / \mathrm{F}$ necessária para a produção de um movimento de coroa em dente com periodonto sadio é de $-8,44$. Com a migração apical do centro de resistência causada pela perda óssea alveolar, é necessário um aumento da relação $\mathrm{M} / \mathrm{F}$ para produzir movimento de corpo do dente. Segundo Bantleon ${ }^{1}$, a perda de $3 \mathrm{~mm}$ de osso alveolar requer um aumento de aproximadamente $20 \%$ nesta relação $\mathrm{M} / \mathrm{F}$ para manter o movimento de corpo. Frente à perda de $8 \mathrm{~mm}$, por exemplo, a relação $\mathrm{M} / \mathrm{F}$ necessária para a produção do mesmo movimento de corpo aumenta para $-12,46^{12}$. Associando-se os conhecimentos expostos até aqui, depreende-se que pacientes adultos com problemas periodontais seriam mais adequadamente tratados com um nível de força menor e com uma biomecânica dirigida para aplicação de força no centro de resistência dos dentes a serem movimentados.

Dentre as preocupações dos ortodontistas, quando da movimentação de dentes na técnica do arco contínuo, uma é freqüentemente subestimada: a dificuldade imposta pelo atrito durante o deslizamento do braquete ao longo do fio. Tal atrito acaba por gerar uma considerável diferença entre a magnitude da força aplicada ao sistema e a que efetivamente é liberada para o ligamento periodontal, o que é conhecido como perda de eficiência. Sabe-se que a chamada resistência friccional influencia a taxa de movimentação ortodôntica, além de aumentar o potencial de perda de ancoragem ${ }^{11}$.

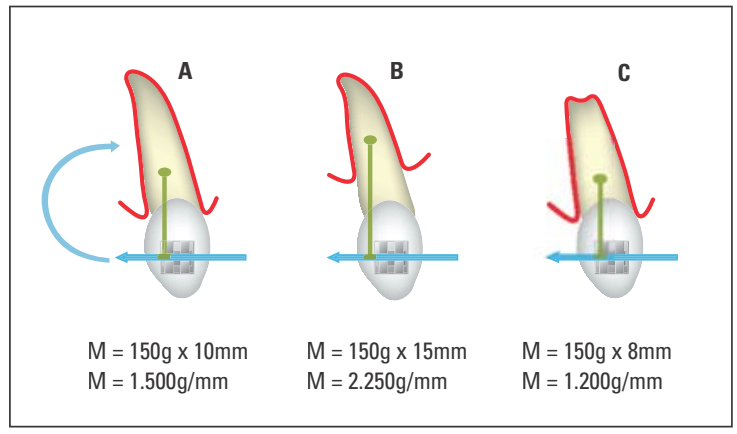

FIGURA 3 - Neste exemplo, uma força distal é aplicada ao canino superior. A tendência de giro do canino (momento) no sentido horário é igual ao produto da magnitude da força pela distância, perpendicular à linha de ação da força, a partir desta linha, até o centro de resistência (A). A mesma magnitude de força aplicada em pacientes com periodonto saudável, quando aplicada a dentes que apresentam perda de sustentação óssea, resulta num momento de magnitude consideravelmente maior (B). Por outro lado, se o dente apresenta uma raiz curta ou reabsorvida, o centro de resistência deste dente migra coronalmente, diminuindo a magnitude do momento (C). 
A fricção, definida como a resistência ao movimento quando objetos se movem tangencialmente um em relação ao outro ${ }^{9}$, foi avaliada para várias combinações de materiais ortodônticos. Braquetes metálicos, de porcelana, de porcelana com slot metálico e braquetes de policarbonato foram testados com fios de aço, beta-titânio e níquel-titânio por diferentes autores, que concluíram que os fios feitos de beta-titânio apresentaram maior resistência friccional que os fios de aço inoxidável e de níquel-titânio; e os braquetes de porcelana com slot do mesmo material apresentaram a maior resistência friccional ${ }^{6,9,11}$.

Os braquetes auto-ligantes de aço e de policarbonato também foram testados. Alguns estudos apresentam resultados que apontam que a friç̧ão é menor em tais braquetes do que em braquetes convencionais ${ }^{4,21,24}$.

Apesar de alguns autores ${ }^{6,27}$ terem concluído, em testes laboratoriais, que as vibrações mastigatórias diminuem a resistência friccional durante a mecânica de deslizamento, Iwasaki et al. ${ }^{15}$ mostraram, através de um estudo clínico, que tal fato não ocorre. Outro resultado desses mesmos autores ${ }^{15}$ diz respeito à forma de amarrar a ligadura metálica. O senso comum indica de que uma ligadura ativada frouxamente pode diminuir o atrito durante o deslizamento. Os autores encontraram uma variação muito grande de forças na ligadura entre os clínicos que participaram do experimento, inclusive em diferentes momentos, quando um mesmo clínico pretendia amarrar com uma força similar, concluindo que o artifício de amarrar a ligadura com menor força não diminui de forma previsivel a friç̧ão.

Quando uma força horizontal (Classe I) é aplicada sobre o braquete em direção distal ou mesial, gera-se um binário na interface braquete/fio, quando este contata diagonalmente os cantos das aletas desse braquete, aumentando assim a resistência friccional ao deslizamento. Tal força também tenderá a girar o dente, até que se estabeleçam contatos entre o fio e a ligadura. Esses eventos diminuem a eficiência mecânica, representada pela diferença entre a força total aplicada e a força liberada. Para Kusy e Whitley ${ }^{17}$, a eficiência varia de $40 \%$ a $88 \%$ com diversas configurações ou combinações fio-braquetes. De forma esperada, alguns trabalhos sustentam que a friç̧ão aumenta com o aumento do calibre do fio $0^{2,6,9,16,20}$, o que torna os fios retangulares utilizados na fase de retração uma solução e um problema na técnica de deslizamento, especialmente quando torques são incorporados ao $\mathrm{fio}^{17}$.

A técnica ortodôntica de deslizamento é provavelmente a mais utilizada atualmente. A praticidade e a simplicidade do manejo de arcos contínuos seduzem muitos clínicos, que vêem nesta mecânica um fator de otimização da sua prática diária, especialmente por conta da diminuição do "tempo de cadeira". No entanto, essa incontestável simplicidade prática oculta ardilosas armadilhas no seu decurso. Como o remédio que se converte em veneno com o erro na dosagem, a facilidade mecânica pode se transmutar em imensa dificuldade clínica, quando não são observados os senões da técnica.

Aos inconvenientes gerados pelo atrito, que aumenta a possibilidade de perda de ancoragem, além de diminuir a eficiência mecânica durante o deslizamento, soma-se o difícil controle da inclinação corono-radicular durante a fase de retração dos dentes anteriores, em casos de extração. Frente a tais situações, o clínico deve estar atento para a necessidade de domínio dos torques nos fios, inclusive em braquetes totalmente programados. Tais torques, especialmente em pacientes com perdas ósseas, como abordado anteriormente, são de difícil mensuração e controle, podendo gerar movimentações indesejadas durante a fase de fechamento de espaços.

\section{O SISTEMA CENTREX SYSTEM (CS)}

O Centrex System (CS) é um sistema ortodôntico que aumenta a eficiência mecânica para movimentação de dentes ou grupos de dentes, 
utilizando a força diretamente no centro de resistência das unidades a serem movimentadas com menor atrito.

O Centrex System propõe a aplicação de menor magnitude de força, com uma movimentação ortodôntica controlada, exatamente pela possibilidade de coincidência da linha de ação da força com o centro de resistência. Assim, o sistema é desenhado para alguns tipos de más oclusões, como a Classe II com ou sem extração e a Classe III, especialmente quando esta é incipiente, com pequeno cruzamento da mordida. Nesses casos de Classe III ainda é possível fazer-se a abertura de espaços para colocação de próteses/implantes, quando foram feitas, previamente, extrações de dentes superiores.

A utilização do sistema pode, ainda, permitir a retração de dentes superiores em casos de Classe II, sem extrações de pré-molares superiores, com o auxílio de um mini-implante inserido próximo ao ápice dos molares, com uma distância aumentada em relação aos ápices dos segundos pré-molares. Esta inserção diferenciada dos miniimplantes permite a movimentação de corpo de todos os dentes superiores, sem prejuízo para os dentes vizinhos.

O Centrex System pode, ainda, ser utilizado como um sistema distalizador padrão, com auxílio de outros dispositivos de ancoragem, como o botão de Nance e a barra palatina. Neste caso, o protocolo de distalização segue os já estabelecidos por outros sistemas distalizadores. A grande vantagem do Centrex System, também neste tipo de caso, é a aplicação da força num ponto mais alto do que todos os outros distalizadores disponiveis atualmente. Isto permite a movimentação de corpo dos molares (movimento de todos os pontos do dente numa única direção e na mesma magnitude) sem a tradicional inclinação descontrolada destes dentes, com a coroa indo para trás (distal) e a raiz para frente (mesial), como acontece nos outros distalizadores que utilizam a linha de ação da força na altura das coroas dentárias.

\section{Descrição do aparelho}

Este aparelho é constituído de um tubo telescópico e um fio com calibre próximo ao calibre da luz do tubo. O fio é redondo e tem calibre de $1,5 \mathrm{~mm}$, sendo a luz do tubo telescópico compatível com este formato. O tamanho do tubo telescópico é de $6 \mathrm{~mm}$, enquanto o fio tem extensão de $25 \mathrm{~mm}$.

As estruturas mencionadas acima (tubo telescópico e fio) são conectadas a fios verticais com $1,5 \mathrm{~mm}$ de calibre e $7 \mathrm{~mm}$ de altura, os quais são unidos a acopladores horizontais adaptáveis ao fio ortodôntico retangular.

No modelo básico, existe um fio vertical, que se estende a partir do fio horizontal, de $1,5 \mathrm{~mm}$ de diâmetro e 4,5mm de altura, com duas depressões no seu corpo, uma na altura de $2 \mathrm{~mm}$ e outra na altura de $4 \mathrm{~mm}$ (Fig. 4).

O dispositivo CS 1 funciona quando a mola exerce pressão no sistema, no sentido da seta (Fig. 5), o que provoca uma força para trás de todo o segmento 1 , juntamente com os dentes anteriores (já que o segmento 1 está conectado a todos os dentes anteriores, através do fio ortodôntico). Enquanto isso, o segmento 2 funciona como um guia para a movimentação ortodôntica. Como a mola está imprimindo a força ortodôntica na altura do CRes dos dentes ântero-superiores, estes dentes movimentar-se-ão para trás, sem inclinação. Isto quer dizer que eles se moverão de corpo (todos os pontos se movem na mesma direção e sentido, na mesma magnitude) (Fig. 5, 6). Este tópico eviden-

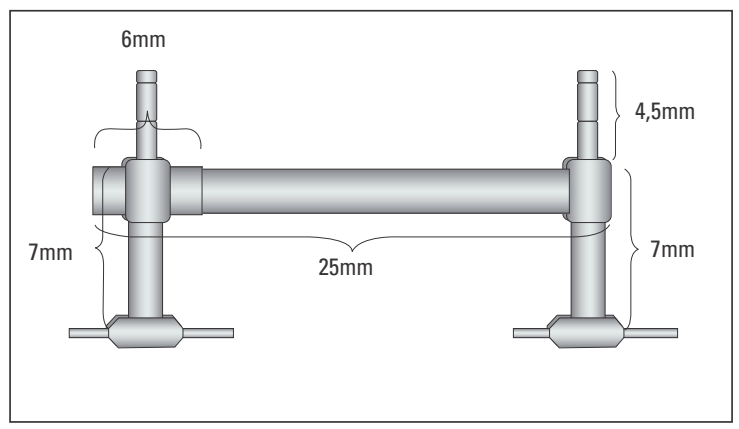

FIGURA 4 - Desenho esquemático representando o modelo básico do apareIho Centrex System 1 (CS 1). 


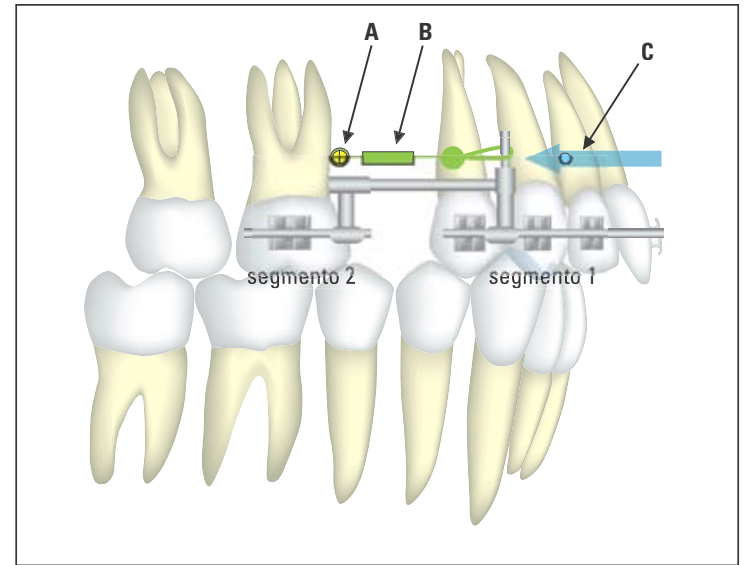

FIGURA 5 - Para entendimento da ativação do Centrex System 1 (CS 1) considere os componentes: A) cabeça do mini-implante; B) mola (recurso que será descrito em um trabalho futuro); C) CRes dos dentes anteriores.

cia a grande vantagem deste aparelho sobre os demais sistemas disponíveis, que aplicam a força na altura da coroa dos dentes, gerando uma tendência de inclinação dos dentes anteriores. Como a força nos outros sistemas é aplicada longe do centro de resistência dos dentes, é inevitável que haja esta tendência de inclinação que, para ser contraposta, exige manobras de torção do fio ortodôntico (torques), aumentando a magnitude da força que atua sobre os dentes. Como exposto anteriormente, este aumento da força não beneficia em nada o sistema, sendo inclusive o grande responsável pelos conhecidos efeitos nocivos sobre as raízes e osso alveolar.

O Centrex System 2 (CS 2) segue o mesmo conceito do CS 1 e é indicado para fechamento de espaços sem o uso de mini-implantes. Este aparelho atua no fechamento de espaços na região intermediária maxilar ou mandibular, fazendo coincidir a linha de ação da força com o centro de resistência dos dentes a serem movimentados (Fig. 7). Nesta situação, a ancoragem passa a ser o segmento posterior, exigindo o aumento de ancoragem através de recursos como o AEB, botão de Nance com barra palatina ou qualquer outro recurso. Não havendo necessidade ou exigência de ancoragem, a retração pode ser conduzida sem a utilização dos recursos citados anteriormente.

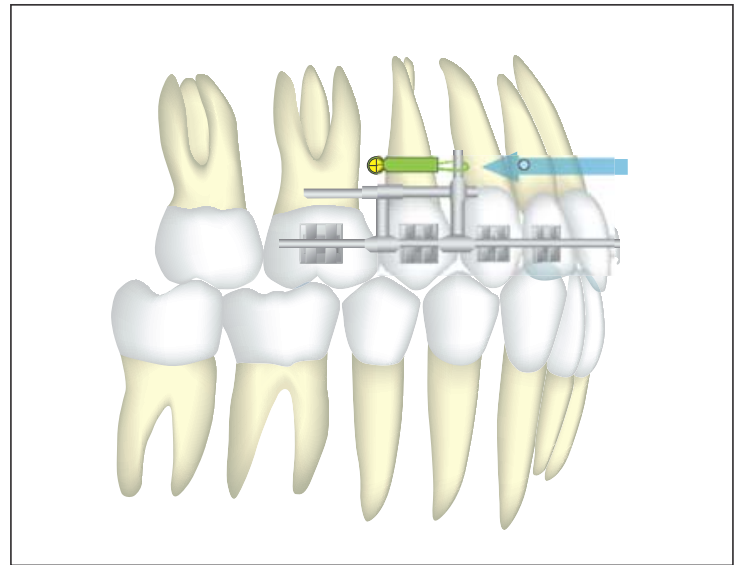

FIGURA 6 - 0 esquema acima mostra o processo de fechamento de espaços, finalizado com o uso do CS 1 .

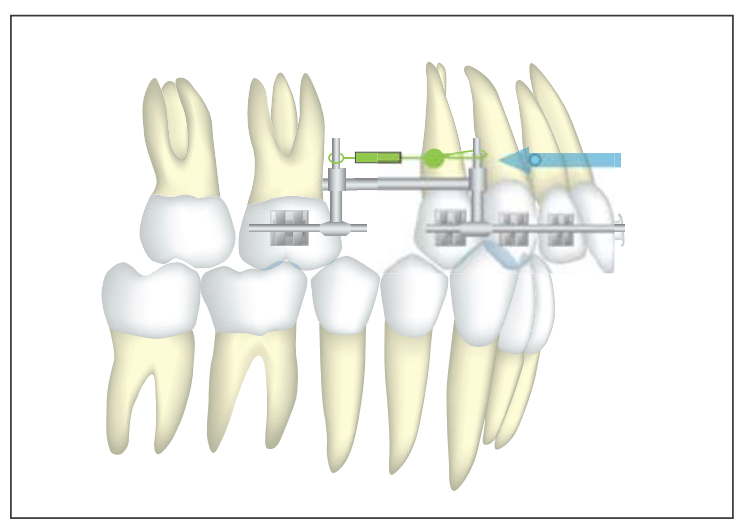

FIGURA 7 - 0 mecanismo de funcionamento do CS 2 difere do CS 1, basicamente, pelo fato de aplicar força em outro fio vertical encaixado no segmento 2 do aparato.

O Centrex System 3 (CS 3) é um sistema para distalizações ou abertura de espaços. Os casos selecionados para utilização deste tipo específico de aparelho são os casos de Classe II sem exodontia, nos quais se busca a distalização dos dentes posteriores para correção da relação molar alterada. Em tais situações, o protocolo de distalização é similar a outros aparelhos que têm o mesmo intuito, ou seja: há a necessidade de se utilizar um botão de Nance ancorado a partir do dente anterior ao dente a ser distalizado. $\mathrm{Na}$ figura 8 , os segundos prémolares superiores são os dentes escolhidos como base do Botão de Nance. 


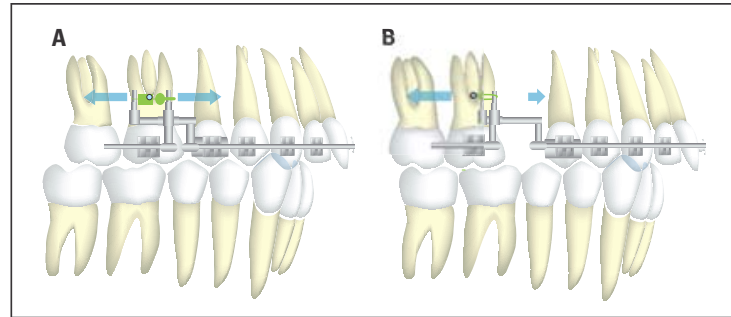

FIGURA 8 - Note que no CS 3 a linha de ação da força passa na altura do Cres dos molares superiores, o que faz com que esses dentes sejam submetidos a um movimento distal de corpo, sem a tendência de momento experimentada em outros tipos de distalizadores (A). 0 resultado final da distalização dos molares superiores pode ser observado em $\mathbf{B}$.

O Centrex System 4 (CS 4) assemelha-se, em função, ao CS 3. O objetivo é a distalização dos dentes posteriores, tendo, nesse caso, como ancoragem o mini-implante inserido mesialmente à raiz do primeiro molar superior (Fig. 9).

\section{CONCLUSÕES}

- A evolução da Ortodontia não pode ficar restrita à repetição de soluções dentro de um mesmo paradigma - do deslizamento tradicional do fio ortodôntico dentro dos slots dos braquetes e tubos ou da mecânica com fios segmentados.

- A mudança paradigmática proposta pressupõe a utilização de um sistema de acessórios que

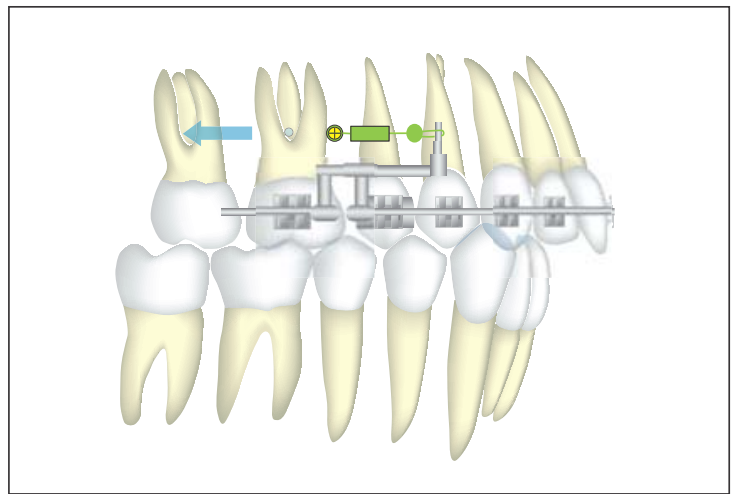

FIGURA 9 - A distalização com o CS 4 serve-se do mini-implante, inserido mesialmente à raiz do primeiro molar superior, como ancoragem para distalizar os molares. Após conseguida a distalização, o mini-implante deve ser relocado posteriormente para permitir a retração dos demais dentes.

eliminaria/diminuiria os efeitos colaterais normalmente observados nas mecânicas tradicionais, tornando o tratamento ortodôntico mais previsível e menos sujeito a efeitos secundários.

- A adoção deste sistema não inviabiliza a utilização de qualquer prescrição ou mesmo tipo ou marca de braquetes que o clínico esteja utilizando, podendo ser adaptado a todas as opções de aparelhos não programados ou totalmente programados existentes no mercado.

Centrex: a proposal of an orthodontic force system on the center of resistance

\begin{abstract}
Aim: This paper introduces a new orthodontic forces system with the objective of decreasing or eliminating some secondary effects of the orthodontic mechanics, such as inclinations, extrusions and anchorage loss. Through a critical literature review on biomechanics of tooth movement, and illustrations of the construction and management of the device, its concept and clinical application are presented. Conclusions: Although other alternatives have been proposed, such as Andrew's "power-arm" or segmented arch mechanics, neither have become unanimous in the daily orthodontic routine. The Centrex might become an alternative to enhance orthodontic mechanics by means of diminishing some of its undesired effects.
\end{abstract}

Key words: Orthodontic anchorage. Mini-implants. Center of resistance. 


\section{REFERÊNCIAS}

1. BANTLEON, H. P. Modified lingual lever arm technique: biomecanical considerations. In: NANDA, R. Biomechanics in clinical Orthodontics. Philadelphia: W. B. Saunders, 1977. p. 5-241.

2. BAZAKIDOU, E.; NANDA, R. S.; DUNCANSON, M. G.; SINHA, P. Evaluation of frictional resistance in esthetic brackets. Am. J. Orthod. Dentofacial Orthop., St. Louis, v. 112, no. 2, p.138144, Aug. 1997

3. BECK, B. W.; HARRIS, E. F. Apical root resorption in orthodontically treated subjects: analysis of edgewise and light wire mechanics. Am. J. Orthod. Dentofacial Orthop., St. Louis, v. 105, no. 2, p. 350-361, Apr. 1994

4. BERGER, J. L. The influence of the Speed bracket's self-ligating design on force levels in tooth movement: a comparative in vitro study. Am. J. Orthod. Dentofacial Orthop., St. Louis, v. 97, no. 3, p. 219-228, Mar. 1990.

5. BOYD, R. L.; LEGGOTT, P. J.; QUINN, R. S.; EAKLE, W. S. CHAMBERS, D. Periodontal implications of orthodontic treatment in adults with reduced or normal periodontal tissues versus those of adolescents. Am. J. Orthod. Dentofacial Orthop., St. Louis, v. 96, no. 4, p. 191-199, Sept. 1989.

6. BRAUN S.; BLUESTEIN M.; MOORE, B. K.; BENSON, G. Friction in perspective. Am. J. Orthod. Dentofacial Orthop., St. Louis, v. 115, no. 6, p. 619-627, June 1999

7. BURSTONE, C. J. Aplicação da bioengenharia na Ortodontia clínica. In: GRABER, T. M.; VANARSDALL JR., R. L. Ortodontia: princípios e técnicas atuais. Rio de Janeiro: Guanabara Koogan, 2002. p. 228-257.

8. BURSTONE, C. J.; BALDWIN, J. J.; LAWLESS, D. T. The application of continuos force to Orthodontics. Angle Orthod. Appleton, v. 31, no. 5, p. 1-14, 1961

9. CACCIAFESTA, V.; SFONDRINI, M. F.; RICCARDI, A.; SCRIBANTE, A.; KLERSY, C.; AURICCHIO, F. Evaluation of friction of stainless steel and esthetic self-ligating brackets in various bracket-archwire combinations. Am. J. Orthod. Dentofacial Orthop., St. Louis, v. 124, no. 4, p. 395-402, Oct. 2003.

10. CORN, H.; MARKS, M. H. Basic biological concepts associated with adult Orthodontics. In: MARKS, M. H.; CORN, H. Atlas of adult Orthodontics. 2nd ed. Philadelphia: Lea. \& Febiger, 1989. p 7-56.

11. DRESCHER, D., BOURAEL, C., SCHUMACHER, H. A. Frictional forces between bracket and arch wire. Am. J. Orthod. Dentofacial Orthop., St. Louis, v. 96, no. 5, p. 397-404, Nov. 1989.

12. GERAMY, A. Alveolar bone resorption and center of resistence modification (3-D analysis by means of finite element method). Am. J. Orthod. Dentofacial Orthop., St. Louis, v. 117, no. 4, p. 399-405, Apr. 2000

13. HOLLENDER, L.; RONNERMAN, A.; THILANDER, B. Root resorption, marginal bone support and clinical crown length in orthodontically treated patients. Eur. J. Orthod., Oxford, v. 54 no. 2, p. 197-205, 1980

14. ISAACSON, R. J.; LINDAUER, S. J.; DAVIDOVITCH, M. As regras básicas para o planejamento dos arcos ortodônticos. In: ISAACSON, et al. Atualidades em Ortodontia. 2. ed. São Paulo: Premier, 1997. p. 5-12.

15. IWASAKI, L. R.: BEATTY, M. W.: RANDALL, C. J.; NICKEL, J. C. Clinical legation forces and intraoral friction during sliding on a stainless steel arch wire. Am. J. Orthod. Dentofacial Orthop. St. Louis, v. 123, no. 4, p. 408-415, Apr. 2003.

16. KAPILA, S.; ANGOLKAR, P. V: DUNCANSON, M. G.; NANDA, R. $S$. Evaluation of friction between Edgewise-stainless steel brackets and orthodontic wires of four alloys. Am. J. Orthod. Dentofacial Orthop., St. Louis, v. 98, no. 2, p. 117-126, Aug. 1990.

17. KUSY, R. P.; WHITLEY, J. Q. O atrito nas diferentes configurações de fio-bracket e materiais. In: SADOWSKY, P. L. Atualidades em Ortodontia. São Paulo: Premier, 2002. p. 177-188.

18. MARCOTTE, M. R. Mecânica em Ortodontia. In: MARCOTTE, M. R. Biomecânica em Ortodontia. São Paulo: Ed. Santos 1992. p. $1-23$
19. McCULLOCH, C. A. G.; MELCHER, A. H. Continuous labelling of the periodontal ligament of mice. J. Periodontal Res. Copenhagen, v. 18, no. 3, p. 231-241, May 1983.

20. OGATA, R. H.; NANDA, R. S.; DUNCANSON JR., M. G.; SINHA, P. K.; CURRIER, G. F. Frictional resistance in stainless steel bracket-wire combinations with effects of vertical deflections. Am. J. Orthod. Dentofacial Orthop., St. Louis, v. 109, no. 5, p. 535-542, May 1996.

21. PIZZONI, L.; RAVNHOLT, G.; MELSEN, B. Frictional forces related to self-ligating brackets. Eur. J. Orthod., Oxford, v. 20, p. 283-291, June 1998

22. PROFFIT, W. R.; FIELDS, H. W.; ACKERMAN, J. L.; SINCLAIR, P. M.; THOMAS, P. M.; TULOCH, J. F. C. Contemporary orthodontics. 2nd ed. Baltimore: C. V. Mosby, 1993.

23. REITAN, K. Tissue behavior during orthodontic tooth movement. Am. J. Orthod. Dentofacial Orthop., St. Louis, v. 46, no. 12, p. 881-900, Dec. 1960.

24. THORSTENSON, G. A.; KUSY, R. P. Resistance to sliding of self-ligating brackets versus conventional stainless steel twin brackets with second-order angulation in the dry and wet (saliva) states. Am. J. Orthod. Dentofacial Orthop., St. Louis, v. 120, no. 4, p. 361-370, Oct. 2001

25. TOMS, S. R.; EBERHARDT, A. W. A nonlinear finite element analysis of the periodontal ligament under orthodontic tooth loading. Am. J. Orthod. Dentofacial Orthop., St. Louis, v. 123, no. 6, p. 657-665, June 2003.

26. TOMS, S. R. LEMONS, J. E.: BARTOLUCCI, A. A : EBERHARDT, A. W. Nonlinear stress-strain behavior of periodontal ligament under orthodontic loading. Am. J. Orthod. Dentofacial Orthop., St. Louis, v. 122, no. 2, p. 174-179, Feb. 2002

27. YAMAGUCHI, K.; NANDA, R. S.; MORIMOTO, N.; ODA, Y. A study of force application, amount of retarding force, and bracket width in sliding mechanics. Am. J. Orthod. Dentofacial Orthop., St. Louis, v. 109, no. 1, p. 50-56, Jan. 1996.

\section{Endereço para correspondência}

José Kleber Soares de Meireles

Av. ACM, 585, sala 504, Bairro Itaigara

CEP: 41.825-000 - Salvador/BA

Email: jksm@uol.com.br 